\title{
Göran Holst
}

Blekinge Institute of Technology, Sweden

\section{Mikael Rennemark}

Linnaeus University, Sweden

\section{Ingalill R. Hallberg}

Lund University, Sweden

\begin{abstract}
Nurses sometimes fail to understand the behaviour of individuals with severe dementia. Information from a next of kin may help to bridge this communicative gap. One factor that influences a person's reaction to a disease is their personality and ability to cope with stress. The aim of this study was to evaluate the inter-rater agreement between healthy elderly people's self-assessment and the assessment made by a next of kin concerning personality and sense of coherence. The participants $(n=154)$ answered questions from the Eysenck Personality Inventory (EPI) and the Antonovsky Sense of Coherence (SOC) scale. The study shows high or moderate agreement in ratings when analysed by means of an intra-class correlation coefficient (range between $r=.57$ and $r=.72$ ) and the results indicate that in general a close relative is able to report on the personality of a next of kin. The inter-rater agreement was high on SOC and extraversion and somewhat lower on neuroticism. For neuroticism, length of time in the relationship increased the odds for a good inter-rater agreement. Thus, seemingly a next of kin is a reliable informant for the elderly in general and is probably also able to add information useful in the nursing care of people with dementia.
\end{abstract}

\section{Keywords}

dementia, personality judgement, family member, sense of coherence 


\section{Introduction}

A communicative gap may develop between a nurse and a person with dementia, for example, due to the patient's reduced ability to communicate (Ripich, 1994), and this means that nurses sometimes have difficulty in understanding and interpreting the meaning of the patient's behaviour. This in turn may lead them to misunderstand the patient's needs and wishes and thus hinder the provision of counteractive care. Information from a secondary source, such as a next of kin, may help to supply supplementary information in areas the patient can no longer tell the carers about. There may also be risks in basing care on knowledge obtained from a secondary source since the reliability of such information is unknown. People in the later stages of a dementia are themselves unable to verify whether information obtained, for example, from a next of kin is trustworthy. Inter-rater reliability cannot be tested in people with dementia because of communication difficulties; however, a first step may be to test the reliability in healthy elderly people.

To provide high-quality care for people with severe dementia, based on respect for their uniqueness, values and philosophy of life (Lövgren, Engström \& Norberg, 1996), nurses need systematically collected information about the patient's personality, habits, likes and dislikes, important life events and coping strategies. Based on such information it may be possible for a nurse to act as what Kenyon and Randall call a guide in the life of a disoriented person (Kenyon \& Randall, 1997). Assembling such information from people with dementia themselves is difficult since they often have reduced communicative abilities, but family members may be able to act as informants thereby providing valuable information for nurses. This study investigated whether healthy people are able to provide reliable information about the personality and coping ability of a next of kin. If this is possible, it can also be assumed that also next of kin information about a demented individual's personality should be informative to nursing care.

In several studies (Archer et al., 2007; Low, Brodaty \& Draper, 2002; Song \& Algase, 2008; Strauss, Lee \& DiFilippo, 1997) a relationship has been found between previous personality and various kinds of behavioural and psychological symptoms in dementia. It therefore seems important to know about the previous life, personality and coping ability of people with dementia when providing care for them. One study (Holst, Hallberg \& Gustafson, 1997) investigated personality before the onset of the dementia disease, as remembered by a close relative, in two groups of severely demented patients. Participants in one group who were regarded as severely demented and seen as vocally disruptive were compared with a similar group of patients with dementia but who were not regarded as disruptive. The previous personalities of the vocally active patients were, as described by a close relative, significantly more often introverted, rigid and emotionally controlled than those in the other group. Thus, people with the former kind of unstable personality may be even more vulnerable in a dementia disease than people in general. Similar findings were reported in a study of 27 individuals with mid- to late-stage dementia which showed a relationship between the patients' emotional regulation style prior to the disease and emotions expressed during the disease (Magai, Cohen, Culver, Gomberg \& Malatesta, 1997). Cohen-Mansfield and Marx also found that demented people who had experienced stressful events, such as a life-threatening experience, or separation from a spouse, exhibited more non-aggressive behaviours, such as pacing (Cohen-Mansfield \& Marx, 1989). 
Another study (Cohen-Mansfield, Marx \& Rosenthal, 1989) showed that agitation during the course of the disease was positively correlated with agitation prior to institutionalization. Thus, there are good reasons for believing that knowledge about the previous personality, ability to handle demands and important life events might be important in understanding the possible meaning of a specific situation for a person with dementia.

Personality can be defined in various ways depending on the theory to which one refers. This study uses the trait theory of personality (Wiggins, 1997) since existing research shows that next-of-kin judgements on traits are useful (Holst et al., 1997). Briefly, traits are consistent patterns of behaviour, feelings and ways of thinking which characterize an individual. Eysenck (1990) has identified extraversion and neuroticism as being traits that constitute two central aspects of an individual's personality. More recently these traits have been widely used in research, being included in the five factor model of personality (Allemand, Zimprich \& Hendriks, 2008; McCae \& Costa, 2005). Extraversion is defined as the tendency to be sociable, active and excitement-seeking. The opposite, introversion, is characterized by quietness, introspection and low risk taking. Neuroticism is defined as being anxious, tensed and irrational. The opposite is emotional stability, calmness and being even-tempered (Pervin, 2001).

It may also be important to know about a person's ability to handle difficult situations and cope with stress. Antonovsky (1979) presented a salutogenic theory of health. He proposed the existence of a general internal factor that determines the way a person appraises and is able to cope with potential stressors. This factor has been labelled 'Sense of Coherence' (SOC) and is defined as a global attitude that expresses one's feelings of confidence concerning comprehensibility, manageability and meaningfulness. Knowledge about an individual's ability to cope with stressful situations is clearly relevant in various situations in dementia care. Morning care during which the patient is highly dependent on help from a nurse, seems for example to be experienced as a series of stressful and threatening events for the patient (Holst, Edberg \& Hallberg, 1999). The patient, because of memory disturbances, has difficulties in understanding why the situation is taking place or what the implication is for their current life (Taylor, 1983) and is, therefore, unable to cope successfully with the situation. There are no studies that focus on people with dementia and their SOC related to their ability to handle stressful events. Several studies have shown that healthy people with a strong SOC tend to manage stress better and keep well, whereas those with a weak SOC are, for example, more vulnerable to poorer health (Larsson, Kallenberg, Setterlind \& Starrin, 1994); caregivers who felt they were less burdened reported better perceived health and had a higher mean score for sense of coherence than caregivers who thought their burden was heavier (Andrén \& Elmståhl, 2008); and in a study of elderly people relations were found between excellent or good self-rated health, high quality of life and a stronger SOC (Borglin, Jakobsson, Edberg \& Hallberg, 2006). Thus, the SOC seem to be important for the person's ability to cope with a stressful event. Assuming that there is a relationship between a person's SOC prior to the debut of dementia and their ability to manage stressful events during the disease it may be helpful for the nurses to know about the patient's SOC prior to onset. The only way to obtain such knowledge is through a secondary source, i.e. a next of kin. Using a personality inventory, Gibson (1971) showed significant correlations between self-ratings and ratings made by a friend in a sample of younger people. Dodwell (1988) compared self-ratings made by 56 people with head injuries with rating made by informants on the Eysenck Personality Inventory (EPI) and found significant correlations between self-rating and informants' ratings for extraversion but 
not neuroticism. No such studies, as far as we know, have been performed for healthy elderly people. Thus, it seems important to test whether a next of kin can serve as a reliable source of information regarding a person's personality and SOC. It may be possible to extrapolate such knowledge to the care of people with a dementia disease.

\section{Aim}

The aim of this study was to evaluate the inter-rater agreement between healthy elderly peoples' self-assessments and assessments made by a next of kin who knew them well, of SOC and the two personality variables: extraversion and neuroticism. The study also aimed to investigate how the kind of relationship (i.e. husband-wife, parent-child), length of relationship, and the age and gender of the people involved affected the inter-rater agreement.

\section{Method}

\section{Subjects}

A sample of pensioners $(n=154)$ was recruited from members of two pensioners' associations in a southern county of Sweden. The criteria for inclusion in the study were being 60 years of age or older (self-informant) and having a second informant available who in their own view knew the self-informant well (Table 1). In Sweden there are a number of associations for pensioners, the two largest being Pensionärernas Riksorganisation (PRO), mainly representing people previously employed in blue-collar work and Svenska pensionärsförbundet (SPF) mainly representing white-collar workers. The self-informants, were all retired and members of PRO $(n=32)$ or SPF $(n=45)$. During the course of four regular meetings of the pensioners' associations, the members were informed about the aim and asked to participate in the study. Some of the pensioners who decided to participate and

Table I. Description of the sample $(n=154)$ divided in the two groups, self-informants $(n=77)$ and second informants $(n=77)$, with regards to age, gender, and type of relationship between the informants

Self-informants $(n=77)$

Age (SD)

Male

Female

Second informants $(n=77)$

Age (SD)

Male

Female

Relationship to self-informants

Husband/wife or cohabiting 
had their husband/wife, cohabiting partner, son/daughter or another person who knew them well with them at the same meeting filled out the questionnaires on the spot. The majority, however, completed the questionnaire in their homes and returned it by mail. In both cases the informants were instructed, verbally and in writing, not to talk to each other before they completed the form. The 2 questionnaires were distributed to 120 pairs: $77(64 \%)$ of them were returned completed and $6(5 \%)$ were returned blank without any comments. In 4 cases a man rated a man; in 13 cases a woman rated a woman; in 33 cases a man rated a woman; and in 27 cases a woman rated a man.

The second informants were husband/wife, cohabiting partner, son/daughter or another person who knew the self-informant well. A majority of the informants $(n=30)$ had known each other for between 11 and 20 years or $(n=28) 21$ years or more and the rest $(n=19)$ had known each other for 5-10 years. The self-informants' ages ranged from 60 to 81 years (mean $=69.8$, standard deviation $[\mathrm{SD}]=5.5)$ and second informants' age ranged between 39 and 83 years $($ mean $=64.8, \mathrm{SD}=10.4)$. There was a majority of females in both groups (Table 1).

\section{Instruments}

Two questionnaires were used for the study, the EPI (Eysenck \& Eysenck, 1964a) and the SOC scale (Antonovsky, 1987). The questionnaires were modified to allow the second informant to respond on behalf of their relative. The first informant answered the original form on behalf of themselves and the second informant answered the modified form of the scale to reflect their view of the first informant.

The Eysenck Personality Inventory. The EPI estimates neuroticism (24 items) and extroversion (24 items). A 9-item scale, called the lie scale, was also included to eliminate the production of a "desirability response set" (Eysenck \& Eysenck, 1964b). The response for each item is either yes or no. Scores can range from 0-24 for extroversion and neuroticism respectively. The higher the value, the more extrovert or neurotic the person is. The EPI was chosen as it is a widely used personality inventory which has previously been shown to be useful in an investigation of the personality before the onset of the dementia disease, as remembered by a close relative (Holst et al., 1997).

The Sense of Coherence scale. The SOC scale estimates the strength of the sense of coherence. It exists in two versions, one consisting of 29 items and a shorter one consisting of 13 items. The shorter version was used in this study. Each item is responded to by choosing a number from 1 (never) to 7 (very often), that best represents the respondent's view of the statement. Scores can range from 13 to 91; the higher the score, the higher the SOC. The properties of the scale have recently been reviewed by (Jakobsson, 2008), and the short version was found to be acceptably reliable and valid.

\section{Analysis}

Differences in ratings between first and second informants were tested using Student's $t$-test for paired samples. Correlations between first and second informants were tested using the Pearson intra-class correlation coefficient. The 5\% level of two-tailed significance was chosen. 
Three hierarchical stepwise logistic regression analyses were performed to determine the factors associated with good agreement between first and second informant scores. The difference in rating scores formed a new variable, extraversion, neuroticism and SOC, respectively, and was used as the dependent variable in the regression analyses and these variables were dichotomized with the upper 25 th percentile as the cut off point. For the independent variables the type of relation was divided into two groups; one where the second informant was the husband/wife or cohabiting partner and a second where the second informant was a child or a close friend. Length of relationship was divided into those who had known each other for less than 10 years and those who had known each other for 11 years or more. Gender and age of first and second informant, and first informant score for extraversion, neuroticism and SOC were also included in the analysis.

\section{Results}

The members of the self-informant group were significantly older than the members of the second informant group ( $p$-value $\& \# 60 ; 0.001$ ) and most of the self-informants were females (Table 1).

There was no statistical difference between the self-informants and the second informants according to their scores for extroversion and SOC. The two groups differed, however, in scores for neuroticism (Table 2). Self-informants scored significantly higher on neuroticism than second informants. In 56 out of the 77 cases $(73 \%)$ the self-raters scored higher compared with the second-raters on the neuroticism scale. On the other two scales the differences in rating were as follows: on extraversion 45 out of $77(59 \%)$ self-informants scored higher and on SOC 34 out of 77 (44\%) scored higher. When tested using the chisquared test, there was a better agreement between self-raters who scored high on neuroticism and there next of kin $(p=0.001)$.

Correlation tests between self-informant and second-informant scores showed a high intra-class correlation correspondence in the ratings on extraversion $(r=.74)$ and neuroticism $(r=.76)$. There was a moderate correspondence on $\operatorname{SOC}(r=.60)$. All correlations were significant at a 0.001 level (Table 3).

The actual difference in scoring between self-informants and second informants can be seen in Table 4. In two of the scales, 23 (30\%) (neuroticism) out of the 77 pairs were identical in their ratings. The majority of the remaining pairs differed by one or two points in their scoring. In the extraversion scale only three of the pairs had identical scoring. The rest of the

Table 2. Mean value score in the EPI variables extraversion (possible range 0-27), neuroticism (possible range 0-27), and SOC ratings (possible score |3-9|) between elderly people's self-rating and next of kin's ratings tested by means of a paired-sample $t$-test

\begin{tabular}{lccccl}
\hline & \multicolumn{2}{c}{ Self-informant $(n=77)$} & \multicolumn{2}{c}{ Second informant $(n=77)$} & p-value \\
\hline Extraversion, mean (SD) & 11.3 & $(3.6)$ & 11.1 & $(2.6)$ & .38 \\
Neuroticism, mean (SD) & 8.1 & $(4.4)$ & 6.8 & $(6.3)$ & $.000^{* * * *}$ \\
SOC, mean (SD) & 73.2 & $(8.6)$ & 74.3 & $(6.3)$ & .35 \\
\hline
\end{tabular}

**** $p<0.001$.

EPI, Eysenck Personality Inventory; SOC, Antonovsky Sense of Coherence scale. 
Table 3. Intra-class correlation coefficient

\begin{tabular}{llll}
\hline & $\begin{array}{l}\text { Extraversion } \\
\text { second rater }\end{array}$ & $\begin{array}{l}\text { Neuroticism } \\
\text { second rater }\end{array}$ & $\begin{array}{l}\text { SOC } \\
\text { second rater }\end{array}$ \\
$\begin{array}{l}\text { Extraversion } \\
\text { Self-rater } \\
\text { Neuroticism } \\
\text { Self-rater }\end{array}$ & $0.74 * * *$ & & \\
SOC & & $0.76 * * *$ & $0.60 * * *$ \\
Self-rater & & & 0.60 \\
\hline
\end{tabular}

$* * * p<0.001$.

SOC, Antonovsky Sense of Coherence scale.

Table 4. Numbers of agreements and disagreements in scoring on the extraversion, neuroticism, social desirability and sense of coherence scales in the self-informant and second-informant groups

\begin{tabular}{lc}
\hline & $\begin{array}{c}\text { Number of agreements or } \\
\text { disagreements in scoring }\end{array}$ \\
\hline Extraversion (0-27) & \\
Identical rating & 3 \\
\pm 1 & 20 \\
\pm 2 & 28 \\
\pm 3 & 17 \\
$\pm 4-5$ & 9 \\
Neuroticism $(0-27)$ & \\
Identical rating & 23 \\
\pm 1 & 34 \\
\pm 2 & 19 \\
\pm 3 & 1 \\
Social desirability $(0-9)$ & \\
Identical rating & 20 \\
\pm 1 & 34 \\
\pm 2 & 21 \\
\pm 3 & 2 \\
Sense of coherence (I3-9I) & \\
Identical rating & 1 \\
$\pm 1-3$ & 13 \\
$\pm 4-6$ & 31 \\
$\pm 7-9$ & 29 \\
$\pm 10-12$ & 5 \\
\pm 13 or more & 3 \\
\hline
\end{tabular}

pairs had a difference of $1-3$ points in their scoring (equivalent to $11 \%$ of the possible variance) on this scale. Finally, for the SOC scale, one pair had identical scoring while the majority of the remaining pairs $(78 \%)$ differed by four to nine points in their scoring (equivalent to $8 \%$ of the possible variance) (Table 4 ). 
Table 5. Logistic regression models showing associations of independent variables with high concordance in rating on the neuroticism scale

\begin{tabular}{|c|c|c|c|c|}
\hline & \multicolumn{2}{|l|}{ Model I } & \multicolumn{2}{|l|}{ Model 2} \\
\hline & Adj OR & $95 \% \mathrm{Cl}$ & Adj OR & $95 \% \mathrm{Cl}$ \\
\hline Self-rater sex & $\mathrm{I} .487$ & $0.422-5.237$ & 1.693 & $0.390-7.339$ \\
\hline Second rater sex & 1.079 & 0.3||$-3.74 \mid$ & 1.211 & $0.285-5.153$ \\
\hline Self-rater age & 1.003 & $0.914-1.101$ & 1.022 & $0.921-1.134$ \\
\hline Second rater age & 1.056 & $1.003-1.112 *$ & 1.062 & $0.996-1.132$ \\
\hline Kind of relationship & & & 1.052 & $0.442-2.619$ \\
\hline Length of relationship & & & $4.45 I$ & $1.235-16.037 *$ \\
\hline Self-rater score on neuroticism & & & 1.248 & $1.04 I-1.496 *$ \\
\hline
\end{tabular}

$*_{p}<0.05$.

Hosmer and Lemeshow goodness-of-fit: model I, $p=0.276$; model 2, $p=0.567$.

Adj OR, adjusted odds ratio; $\mathrm{Cl}$, confidence interval.

The logistic regression analyses showed (Table 5) that those pairs who had known each other for a long time had a more than four times better chance of making the same assessments (Exp-B 4.451, $p=0.022$ ) and when the self-informant had a high score on neuroticism there were also a significantly better chance of an identical score (Exp-B $1.240, p=0.016)$.

\section{Discussion}

The rationale for this study was to evaluate whether a next of kin might be able to provide reliable information about the personality and SOC of a person they knew well and who had severe dementia, i.e. a person unable to speak for themselves. The findings indicate that the hypothesis, i.e. the idea that a next of kin can act as a reliable source for such information cannot be rejected at least when both parties are healthy. However, it is important to note that this study does not include anyone with dementia. The experience of dementia may affect caregivers' ratings, for example in that they idealize the personality and coping ability of the sick person.

In this study the pairs were rating the current situation, i.e. their current apprehension of their own and actual personality and SOC and the next of kin's assessment of the same. When transferred to dementia care the reliability in information about personality may be biased in one way or another by the fact that information is provided retrospectively, i.e. the information is about the personality prior to the onset of the disease. This possible bias should be considered before the results are transferred from healthy to demented individuals.

The difference in scores between first and second informants and the intra-class correlation coefficients, analysing the relation between self- and second informant scoring, support the idea that a next of kin's assessment of a close relative's personality, as measured by extraversion $(r=.70)$ in the EPI may be fairly reliable in relation to the measurement made by the persons themselves. The findings concerning the neuroticism scale point in the same direction since a majority of the pairs were identical or almost identical in their rating and the intra-class correlation coefficient also showed a high correlation $(r=.72)$. When judging neuroticism, however, the self-informants had significantly higher scores than 
the second informants, showing that a second informant tends to underestimate that personality style.

It may be easier to judge a personality trait such as extraversion, since it is a part of personality that is expressed in overt behaviour. Neuroticism and SOC, on the other hand, are internal processes, affection and feelings for example and for that reason are not so easy for an outsider to grasp.

The results are based on answers from a sample of 77 elderly people (aged 60 or older) and one of their next of kin. The size of the sample and the sampling method can be criticised as a weak form of sampling because of the risk of bias, especially if the phenomenon under investigation is heterogeneous in nature within the population. However, personality and SOC, the phenomena in focus in this study, are probably fairly homogeneous in the population and therefore the risk of bias ought to be acceptable. The relationship between the measures in the study is described through a correlation procedure. The product-moment correlation coefficient, Pearson's $r$, was used since the scores were mostly distributed normally. It is also difficult to determine whether a relationship should be interpreted as strong or weak. Referring to Polit and Hungler (1995) correlation coefficients between variables of a social or psychological nature with an $r$ above 70 is high. From a clinical perspective the difference in scoring is probably important, i.e. assessments for extraversion and neuroticism were the same or differed by up to three scale steps between the two assessors. Thus, a next of kin seems to be a fairly reliable informant for the elderly in general and is also probably able to add information useful in the nursing care of people with dementia.

The study showed that those pairs who had known each other for a long time more often made identical assessments for neuroticism and when the self-informant had high score for neuroticism there was also somewhat better chance of having identical scores on the neuroticism scale. The length of the relationship seemingly contributes to the phenomenon of 'knowing each other's personality style well'; however, such understanding is probably also a product of other qualities in the relationship between people.

On the other hand, the result showed no difference in concordance in judging extraversion or SOC between those who had known each other for a long time and those who had known each other for 10 years or less. Thus, the question of whether it is easier for a second informant to judge the personality and sense of coherence if they have known the first informant for a long time seems complex. An explicitly 'neurotic personality' might be easier to recognize. However, the study fails to guide practitioners regarding whether or not it is important for nurses in dementia care to know how long the person with dementia and their next of kin have known each other. The duration of the relation might be one factor but the focus should perhaps be on how they know each other and the quality of their relationship. The rather high confidence interval seen for length of relation (Table 5) indicates that there might also be other factors influencing the ability to make an identical assessment.

One important question is whether or not the results from this study are applicable to the care of people with a dementia disease. In developing individualized care it is important to focus on and enquire about the needs and wishes of the individual patient. It is difficult, however, to obtain such knowledge from a person with dementia because of the lack of communication between her/him and the nurse.

Other studies (Berg, Hallberg \& Norberg, 1998; Holst et al., 1999) have found that nurses make their own interpretations of what is in the interest of the person with dementia. This 
interpretation may be mistaken and misleading. As a complement to the nurse's own interpretation of what is, for example, of interest to the patient or what a certain behaviour might communicate, it is possible to open the way for alternative interpretations by discussing the situation with colleagues during, for example, clinical supervision or by discussing things with a relative. Therefore, when providing care for people with dementia it is also necessary for the nurses to obtain knowledge from sources other than themselves. Characteristic personality seems to be one of several factors to take into consideration when providing individualized care for people with dementia. Systematically collected knowledge about the patient's previous personality, including such aspects as their strength in handling stress may be one way of helping the nurse to interpret some of the behaviours and reactions that people with dementia exhibit during the course of the disease. This study shows that a person's next of kin might be a fairly reliable source of information and that they may be helpful to nurses by providing information about their close relative's personality.

\section{Acknowledgements}

We are grateful to the participants for their cooperation in the data collection and to Patricia Shrimpton for revising the English.

\section{Funding}

This study was supported by the Blekinge County Council and Greta and Johan Koch's Memorial Fund.

\section{References}

Allemand, M., Zimprich, D., \& Hendriks, A. A. (2008). Age differences in five personality domains across the life span. Developmental Psychology, 44, 758-770.

Andrén, S., \& Elmståhl, S. (2008). The relationship between caregiver burden, caregivers' perceived health and their sense of coherence in caring for elders with dementia. Journal of Clinical Nursing, 17, 790-799.

Antonovsky, A. (1979). Health stress and coping. San Francisco, CA: Jossey-Bass.

Antonovsky, A. (1987). Unraveling the mystery of health. San Francisco, CA: Jossey-Bass.

Archer, N., Brown, R. G., Reeves, S. J., Boothby, H., Nicholas, H., Foy, C., et al. (2007). Premorbid personality and behavioral and psychological symptoms in probable Alzheimer disease. The American Journal of Geriatric Psychiatry: Official Journal of the American Association For Geriatric Psychiatry, 15, 202-213.

Berg, A., Hallberg, I. R., \& Norberg, A. (1998). Nurses' reflections about dementia care, the patients, the care and themselves in their daily caregiving. International Journal of Nursing Studies, 35, 271-282.

Borglin, G., Jakobsson, U., Edberg, A. K., \& Hallberg, I. R. (2006). Older people in Sweden with various degrees of present quality of life: their health, social support, everyday activities and sense of coherence. Health \& Social Care in the Community, 14, 136-146.

Cohen-Mansfield, J., \& Marx, M. S. (1989). Do past experiences predict agitation in nursing home residents? International Journal of Aging and Human Development, 28, 285-294.

Cohen-Mansfield, J., Marx, M. S., \& Rosenthal, A. S. (1989). A description of agitation in a nursing home. Journal of Gerontology, 44(3), M77-M84.

Dodwell, D. (1988). Comparison of self-ratings with informant-ratings of pre-morbid personality on two personality rating scales. Psychological Medicine, 18, 495-501. 
Eysenck, H. (1990). Biological dimensions of personality. In L. Pervin (Ed.), Handbook of personality: Theory and research. New York: Guilford Press.

Eysenck, H., \& Eysenck, S. (1964a). Manual of the Eysenck Personality Inventory. Kent: Hodder and Stoughton.

Eysenck, S., \& Eysenck, H. (1964b). Acquiescence response set in personality inventory items. Psychological Reports, 14, 513-514.

Gibson, H. B. (1971). The validity of the Eysenck personality inventory studies by a technique of peerrating item by item, and by sociometric comparisons. The British Journal of Social and Clinical Psychology, 10, 213-220.

Holst, G., Edberg, A. K., \& Hallberg, I. R. (1999). Nurses narrations and reflections about caring for patients with severe dementia as revealed in systematic clinical supervision sessions. Journal of Aging Studies, 13, 89-107.

Holst, G., Hallberg, I. R., \& Gustafson, L. (1997). The relationship of vocally disruptive behavior and previous personality in severely demented institutionalized patients. Archives of Psychiatric Nursing, $11,147-154$.

Jakobsson, U. (2008). A brief review of the development and psychometric properties of sense of coherence scale (SOC). Vård I Norden, 28, 53-55.

Kenyon, G., \& Randall, W. (1997). Restorying our lives. Personal growth through autobiographical reflection. London: Praeger.

Larsson, G., Kallenberg, K., Setterlind, S., \& Starrin, B. (1994). Health and loss of a family member: impact of sense of coherence. International Journal of Health Studies, 5, 5-11.

Lövgren, G., Engström, B., \& Norberg, A. (1996). Patients' narratives concerning good and bad caring. Scandinavian Journal of Caring Sciences, 10, 151-156.

Low, L. F., Brodaty, H., \& Draper, B. (2002). A study of premorbid personality and behavioural and psychological symptoms of dementia in nursing home residents. International Journal of Geriatric Psychiatry, 17, 779-783.

Magai, C., Cohen, C. I., Culver, C., Gomberg, D., \& Malatesta, C. (1997). Relation between premorbid personality and patterns of emotion expression in mid- to late-stage dementia. International Journal Of Geriatric Psychiatry, 12, 1092-1099.

McCae, R., \& Costa, P. Jr (2005). Personality in adulthood: A five factor theory perspective. Guilford Publication Inc.

Pervin, L. (2001). Personality: Theory and research. New York: John Wiley \& Sons Inc.

Polit, D., \& Hungler, B. (1995). Nursing research, principles and methods (Vol. 5) J.B. Lippincott Company.

Ripich, D. N. (1994). Functional communication with AD patients: a caregiver training program. Alzheimer Disease And Associated Disorders, 8(Suppl. 3), 95-109.

Song, J. A., \& Algase, D. (2008). Premorbid characteristics and wandering behavior in persons with dementia. Archives of Psychiatric Nursing, 22, 318-327.

Strauss, M. E., Lee, M. M., \& DiFilippo, J. M. (1997). Premorbid personality and behavioral symptoms in Alzheimer disease. Some cautions. Archives of Neurology, 54, 257-259.

Taylor, S. (1983). Adjustment to threatening events. A theory of cognitive adaption. American Psychologist, 38, 1161-1173.

Wiggins, J. (1997). In defense of traits. In R. Hogan, L. Johnsson, \& S. Biggs (Eds.), Handbook of personality psychology. New York: Academic Press.

Göran Holst, from the Blekinge Institute of Technology, School of Health Science, is associate professor in nursing and has a long-standing experience in research and development related to elderly people with dementia and their families. In addition to teaching at the nursing program, he is supervisor in several research and development projects in the field of dementia care. 
Mikael Rennemark, from the Linnaeus University, is associate professor in psychology. His main research interest is on the role of psychological and social factors on healthy ageing. He is participating in the Swedish National Study on Ageing and care (SNAC) and in education and research on health psychology and public health science.

Ingalill R. Hallberg, from the Lund University, the Medical Faculty, has a longstanding experience in research related to the elderly, their health care and social service and also to people suffering from dementia. In particular she has been involved in research regarding understanding the development of Behavioral and Psychological Symptoms of Dementia (BPSD) and its relation to the care provided. Currently she is the Swedish PI to a EU FP7 funded study on best practice in care of people with a dementia disease: 'Right time, care and place'. 